\title{
Molecular characterization of vulnibactin biosynthesis in Vibrio vulnificus indicates the existence of an alternative siderophore
}

\author{
Wenzhi Tan ${ }^{1}$, Vivek Verma ${ }^{1}$, Kwangjoon Jeong ${ }^{1}$, Soo Young Kim ${ }^{1}$, Che-Hun Jung ${ }^{2}$, Shee Eun Lee ${ }^{1,3}$ \\ and Joon Haeng Rhee ${ }^{1 *}$
}

'Department of Microbiology, Clinical Vaccine R\&D Center, Chonnam National University Medical School, Gwangju, South Korea
2 Department of Chemistry, Chonnam National University College of Natural Science, Gwangju, South Korea
${ }^{3}$ Department of Pharmacology and Dental Therapeutics, School of Dentistry, Chonnam National University, Gwangju, South Korea

Edited by:

Daniela Ceccarelli, University of

Maryland, USA

Reviewed by:

Jesus L. Romalde, Universidad de

Santiago de Compostela, Spain

Daniele Provenzano, University of

Texas Brownsville, USA

*Correspondence:

Joon Haeng Rhee, Department of Microbiology, Clinical Vaccine R\&D

Center, Chonnam National

University Medical School, Gwangju

501-746, South Korea

e-mail: jhrhee@chonnam.ac.kr
Vibrio vulnificus is a halophilic estuarine bacterium that causes fatal septicemia and necrotizing wound infections in humans. Virulent $V$. vulnificus isolates produce a catechol siderophore called vulnibactin, made up of one residue of 2, 3-dihydroxybenzoic acid (2, 3-DHBA) and two residues of salicylic acid (SA). Vulnibactin biosynthetic genes (VV2_0828 to VV2_0844) are clustered at one locus of chromosome 2, expression of which is significantly up-regulated in vivo. In the present study, we decipher the biosynthetic network of vulnibactin, focusing specifically on genes around SA and 2 , 3-DHBA biosynthetic steps. Deletion mutant of isochorismate pyruvate lyase (VV2_0839) or 2, 3-dihydroxybenzoate-2, 3-dehydrogenase (VV2_0834) showed retarded growth under iron-limited conditions though the latter showed more significant growth defect than the former, suggesting a dominant role of 2, 3-DHBA in the vulnibactin biosynthesis. A double deletion mutant of VV2_0839 and VV2_0834 manifested additional growth defect under iron limitation. Though the growth defect of respective single deletion mutants could be restored by exogenous SA or 2, 3-DHBA, only 2, 3-DHBA could rescue the double mutant when supplied alone. However, double mutant could be rescued with SA only when hydrogen peroxide was supplied exogenously, suggesting a chemical conversion of SA to 2, 3-DHBA. Assembly of two SA and one 2, 3-DHBA into vulnibactin was mediated by two AMP ligase genes (VV2_0836 and VV2_0840). VV2_0836 deletion mutant showed more significant growth defect under iron limitation, suggesting its dominant function. In conclusion, using molecular genetic analytical tools, we confirm that vulnibactin is assembled of both 2, 3-DHBA and SA. However, conversion of SA to 2, 3-DHBA in presence of hydrogen peroxide and growth profile of AMP ligase mutants suggest a plausible existence of yet unidentified alternative siderophore that may be composed solely of 2, 3-DHBA.

Keywords: V. vulnifiucus, siderophore, salicylate, 2, 3-DHBA, hydroxyl radical, AMP ligase

\section{INTRODUCTION}

Vibrio vulnificus is an opportunistic Gram-negative bacterial pathogen that causes fatal septicemia and necrotizing wound infections in susceptible individuals with high serum iron levels (Strom and Paranjpye, 2000). Due to its vital role as a redox cofactor of proteins, iron is an essential micronutrient for most life forms. Since iron availability is limited in biological systems, pathogenic bacteria have evolved an array of intricate mechanisms to scavenge iron from the host (Skaar, 2010). The low molecular weight compound called siderophore binds iron with high affinity (Braun and Killmann, 1999) and is an important virulence factor produced by V. vulnificus (Morris et al., 1987; Litwin et al., 1996). Virulent $V$. vulnificus produces a phenolate (catechol) siderophore called vulnibactin that enables it to acquire iron from highly iron saturated host proteins such as transferrin (Stelma et al., 1992).
Vulnibactin was reported to be composed of one residue of 2, 3-DHBA and two residues of salicylic acid (SA), both of which are involved in the formation of oxazoline rings with Lthreonine, which is bound to a norspermidine backbone (Okujo et al., 1994). The chemical structure of vulnibactin is closely related to the Vibrio cholerae catechol siderophore, vibriobactin. Vibriobactin was reported to be composed of three residues of 2,3-DHBA, and like vulnibactin its biosynthesis was also found to be dependent on non-ribosomal peptide synthatases (NRPS) (Griffiths et al., 1984; Keating et al., 2000). Hence, it is highly likely that synthesis of 2, 3-DHBA in V. vulnificus is similar to that of Vibrio cholerae. The most important precursor in NRPS-dependent siderophore biosynthetic pathway is chorismate. 2, 3-DHBA could be formed from chorismate by a three step reaction catalyzed by isochorismate synthase (Liu et al., 1990), isochorismatase (Rusnak et al., 1990; Litwin et al., 
1996), and 2, 3-dihydroxybenzoate-2, 3-dehydrogenase (Liu et al., 1989; Nahlik et al., 1989). Salicylate is a powerful scavenger of highly reactive hydroxyl radicals, resulting in its non-enzymatic conversion to 2, 3-DHBA, 2, 5-DHBA and catechol, with the ratio of these products dependent upon iron concentrations and pH (Hiller et al., 1983; Halliwell et al., 1988; Maskos et al., 1990; Chang et al., 2008). In bacteria, like 2, 3-DHBA, salicylate could also be derived from chorismate. In Pseudomonas aeruginosa and Pseudomonas fluorescens, isochorismate synthase and an isochorismate pyruvate lyase were identified as being responsible for salicylate biosynthesis (Gaille et al., 2002, 2003). 2, 3-DHBA and salicylate are subsequently activated by AMP ligase as precursors for siderophore assembly (Keating et al., 2000; Khalil and Pawelek, 2011). In V. vulnificus, the genes encoding above-mentioned enzymes are located at a single gene cluster in the chromosome 2 (Figure 1A). Previously, by an in vivo transcriptome analysis we observed a significantly up-regulated expression of the genes in this cluster (Rhee, unpublished data). In the present study, using molecular genetics tools, we characterize the vulnibactin biosynthetic pathway highlighting the contribution of 2, 3-DHBA and SA to vulnibactin biosynthesis in V. vulnificus. We focus on four genes in the mentioned gene cluster (Figure 1A) i.e., VV2_0834 (2,3-dihydroxybenzoate2, 3-dehydrogenase), VV2_0839 (isochorismate pyruvate lyase), and two genes encoding putative AMP ligases (VV2_0836 and VV2_0840) for activation of 2, 3-DHBA or SA. By gene deletion and respective in-trans complementation studies we establish the essentiality of these genes in bacterial virulence. Further, by exogenously supplying the products of deleted genes, we found that 2, 3-DHBA is more important than SA for growth under iron limited conditions, and endogenously synthesized SA could serve as a scavenger of hydroxyl radicals, supplying 2, 3-DHBA for siderophore biosynthesis. Furthermore, we cloned and purified VV2_0836 and VV2_0840 encoded AMP ligases and found that both of these enzymes are capable of activating 2, 3-DHBA and SA, and their essentiality for siderophore biosynthesis is dependent on iron levels. By way of molecular dissection of various pathways of siderophore synthesis in $V$. vulnificus we envisage the existence of an alternative siderophore composed solely of 2 , 3-DHBA.

\section{MATERIALS AND METHODS BACTERIAL STRAINS, PLASMIDS, AND GROWTH CONDITIONS}

Bacterial strains and plasmids used in the present study are enlisted in Table 1. V. vulnificus CMCP6 is a clinical isolate from a male patient, isolated at the Chonnam National University Hospital, South Korea. V. vulnificus CMCP6 was grown in $2.5 \% \mathrm{NaCl}$ heart infusion (HI) medium while Escherichia coli strains were grown in Luria-Bertani (LB) medium supplemented appropriately with antibiotics. Bacteria were grown at $37^{\circ} \mathrm{C}$ under shaking conditions $(200 \mathrm{rpm})$. Thiosulfate citrate bile salt sucrose agar (TCBS) (Merck, Darmstadt, Germany) was used as the selective medium for $V$. vulnificus. For E. coli, antibiotics were used at the following concentrations: ampicilin (Amp) $100 \mu \mathrm{g} / \mathrm{ml}$, kanamycin $(\mathrm{Km}) 100 \mu \mathrm{g} / \mathrm{ml}$, chloramphenicol $(\mathrm{Cm})$ $30 \mu \mathrm{g} / \mathrm{ml}$, and tetracycline (Tc) $12.5 \mu \mathrm{g} / \mathrm{ml}$. For V. vulnificus, Amp $(20 \mu \mathrm{g} / \mathrm{ml})$, Tc $(2 \mu \mathrm{g} / \mathrm{ml})$ and $\mathrm{Cm}(2 \mu \mathrm{g} / \mathrm{ml})$ were used. To assess the growth of bacteria under iron-limited conditions, overnight grown bacterial cultures in HI medium were washed twice with phosphate buffered saline (PBS, $\mathrm{pH}$ 7.2) and inoculated into fresh HI broth supplemented with various concentrations of 2, 2-dipyridyl (DP) (Sigma) to a final concentration of $5 \times$ $10^{5} \mathrm{CFU} / \mathrm{ml}$. The optical density at $600 \mathrm{~nm}\left(\mathrm{OD}_{600}\right)$ was measured spectrophotometerically (Ultrospec 6300 Pro, Amersham Biosciences) at selected time points.

\section{CONSTRUCTION OF IN-FRAME DELETION MUTANTS BY HOMOLOGOUS RECOMBINATION METHOD}

The chromosomal in-frame deletion mutants of VV2_0834, VV2_0839, VV2_0836, and VV2_0840 were constructed in V. vulnificus by allelic exchange method (Miller and Mekalanos, 1988). Primers used for PCR reactions are enlisted in Table 2. As per requirement, PCR primers were synthesized with overhangs recognized by specific restriction enzymes (REs) for

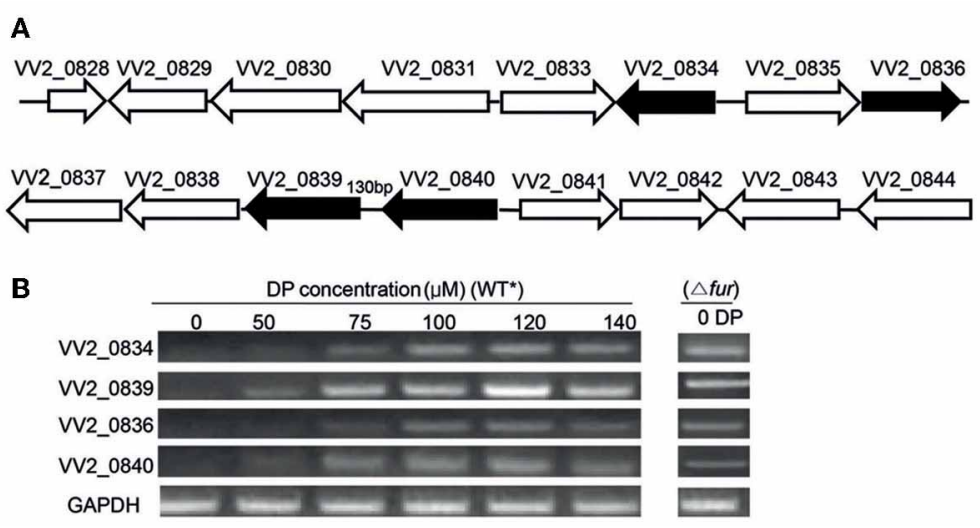

FIGURE 1 | Gene organization and expression under various iron concentrations. (A) Organization of Open Reading Frames (ORFs) in the vulnibactin biosynthetic gene cluster located on chromosome 2 of $V$. vulnificus. ORFs filled in black represent the genes of focus in the present study. (B) RT-PCR estimated expression of VV2_0834, V2_0839, WV2_0836, and VV2_0840 in wild type and Fur regulator mutant grown in $2.5 \% \mathrm{NaCl}-\mathrm{HI}$ supplemented with various DP concentrations. *wild type. 
Table 1 | Strains and plasmids used in this study.

\begin{tabular}{|c|c|c|}
\hline Strain or plasmid & Description & Source/references \\
\hline \multicolumn{3}{|l|}{ BACTERIAL STRAINS } \\
\hline V. vulnificus CMCP6 & $\begin{array}{l}\text { Clinical isolate from a } \\
\text { septicemic patient }\end{array}$ & Kim et al., 2011 \\
\hline$\Delta 20834$ & $\begin{array}{l}\text { CMCP6 with deletion of } \\
\text { VV2_0834 }\end{array}$ & This study \\
\hline$\Delta 20839$ & $\begin{array}{l}\text { CMCP6 with deletion of } \\
\text { WV2_0839 }\end{array}$ & This study \\
\hline$\Delta 20836$ & $\begin{array}{l}\text { CMCP6 with deletion of } \\
\text { VV2_0836 }\end{array}$ & This study \\
\hline$\Delta 20840$ & $\begin{array}{l}\text { CMCP6 with deletion of } \\
\text { WV2_0840 }\end{array}$ & This study \\
\hline$\Delta 20839 / 20834$ & $\begin{array}{l}\text { CMCP6 with deletion of } \\
\text { VV2_0839 and VV2_0834 }\end{array}$ & This study \\
\hline$\Delta 20836 / 20840$ & $\begin{array}{l}\text { CMCP6 with deletion of } \\
\text { VV2_0836 andVV2_0840 }\end{array}$ & This study \\
\hline$\Delta$ fur & $\begin{array}{l}\text { CMCP6 with deletion of fur } \\
\text { gene }\end{array}$ & This study \\
\hline \multicolumn{3}{|l|}{ E. coli } \\
\hline $\mathrm{DH} 5 \alpha$ & F-recA 1 ; restriction negative & ATCC \\
\hline SY327 $\lambda$ pir & $\begin{array}{l}\Delta \text { (lac pro) argE (Am) rif nalA } \\
\text { recA56 } \lambda \text { pir lysogen; host } \\
\text { for } \pi \text {-requiring plasmids }\end{array}$ & $\begin{array}{l}\text { Miller and } \\
\text { Mekalanos, } 1988\end{array}$ \\
\hline SM10 $\lambda$ pir & $\begin{array}{l}\text { thi thr leu tonA lacY supE } \\
\text { recA::RP4-2-TcR::Mu } \\
\lambda \text { pirlysogen, oriT of RP4, } \\
\mathrm{Km}^{r} \text {; Conjugal donor }\end{array}$ & $\begin{array}{l}\text { Miller and } \\
\text { Mekalanos, } 1988\end{array}$ \\
\hline \multicolumn{3}{|l|}{ PLASMIDS } \\
\hline pDM4 & $\begin{array}{l}\text { A suicide vector with ori R6K } \\
\text { sacB and } \mathrm{Cm}^{r}\end{array}$ & Milton et al., 1996 \\
\hline pLAFR3II & $\begin{array}{l}\text { pLAFR3 with bla instead of } \\
\text { cos site }\end{array}$ & Simon et al., 1983 \\
\hline pRK2013 & $\begin{array}{l}\text { IncP } K m^{r} \text { Tra Rk2_repRK2 } \\
\text { repE1 }\end{array}$ & Ditta et al., 1980 \\
\hline pTYB12 & $\begin{array}{l}\text { N-terminal fusion expression } \\
\text { vector in which the } \mathrm{N} \\
\text { terminus of a target protein } \\
\text { is a fused intein tag; } A p^{r}\end{array}$ & $\begin{array}{l}\text { New England } \\
\text { Biolabs, Inc. }\end{array}$ \\
\hline c20834 & $\begin{array}{l}\text { Fragment containing } \\
\text { VV2_0834 cloned into } \\
\text { pLAFR3II }\end{array}$ & This study \\
\hline c20839 & $\begin{array}{l}\text { Fragment containing } \\
\text { VV2_0839 cloned into } \\
\text { pLAFR3II }\end{array}$ & This study \\
\hline c20836 & $\begin{array}{l}\text { Fragment containing } \\
\text { VV2_0836 cloned into } \\
\text { pLAFR3II }\end{array}$ & This study \\
\hline c20840 & $\begin{array}{l}\text { Fragment containing } \\
\text { VV2_0840 cloned into } \\
\text { pLAFR3II }\end{array}$ & This study \\
\hline
\end{tabular}

$\mathrm{Cm}^{r}, \mathrm{Cm}$ resistance; $\mathrm{Tc}^{r}, \mathrm{Tc}$ resistance; $\mathrm{Ap}^{r}$, Ap resistance; $\mathrm{Km}{ }^{r}, \mathrm{Km}$ resistance.

ligation into appropriate vectors. Upstream and downstream 1000 base pair (bp) fragments of target genes were amplified separately and converted to $2 \mathrm{kbp}$ fragments by cross over PCR (Horton et al., 1989). Fusion fragments were digested

Table 2 | Primers used in the present study.

Function and Nucleotide sequence $\left(5^{\prime}\right.$ to $\left.3^{\prime}\right)$
name

\begin{tabular}{ll}
\hline CONSTRUCTION OF VV2_0834 DELETION \\
834-UF*(Sacl) & GACCGAGCTCAGGATGGAAAGGGCTGAT \\
834-UR** & GATAACGTTTTTATGTAATAACTTGCTGAAGCA \\
834-DF\# & TTCAGCAAGTTATTACATAAAAACGTTATCTCT \\
834-DR\#\# & GCGGGCCCGAACCGGCCAGCGGATTG
\end{tabular}

(Apal)

CONSTRUCTION OF VV2_0839 DELETION

$\begin{array}{ll}\text { 839-UF (Spel) } & \text { GGACTAGTGGCGTTGGTGCCTGCATT } \\ \text { 839-UR } & \text { CGAGTGATAAGCTACACGGTTATTTCCTTTCG } \\ \text { 839-DF } & \text { AGGAAATAACCGTGTAGCTTATCACTCGTAAA } \\ \text { 839-DR (Apal) } & \text { GCGGGCCCTTCACACTTAGGCGACGG } \\ \text { CONSTRUCTION OF VV2_0836 DELETION } \\ \text { 836-UF (Sacl) } & \text { GCCGAGCTCGCGAATCAGACAATCCGG } \\ \text { 836-UR } & \text { TACTTTTCGCTACTACATGCCGATACCTTATGC } \\ \text { 836-DF } & \text { TAAGGTATCGGCATGTAGTAGCGAAAAGTAAGT } \\ \text { 836-DR (Apal) } & \text { GTGGGCCCTAACAACGTCAGCTAGGC }\end{array}$

\section{CONSTRUCTION OF VV2_0840 DELETION}

840-UF (Sacl)

840-UR

840-DF

840-DR (Apal)

\section{COMPLEMENTATION}

836-F (EcoRI)

836-R (Sall)

840-F (BamHI)

840-R (EcoRI)

\section{RT-PCR}

RT-839F

RT-839R

RT-836F

RT-836R

RT-840F

RT-840R

RT-834F

RT-834R

\section{RECOMBINANT PROTEIN CONSTRUCTION}

836-F (EcoRI)

836-R (Sall)

$840-\mathrm{F}$ (Ndel)

840-R (EcoRI)

Underlined sequences indicate the RE recognition sites with their respective names written in parenthesis. ${ }^{*}$ Up forward, ${ }^{* *}$ Up reverse, "Down forward, \#\#Down reverse.

with appropriate REs and subcloned into pDM4 suicide vector. The resulting recombinant vector was transformed into E. coli SM10 $\lambda$ pir and subsequently mated into V. vulnificus CMCP6 by conjugation. Stable $\mathrm{Cm}^{R}$ transconjugants were selected on TCBS agar plate containing $\mathrm{Cm}$. Plating of the transconjugants on $2.5 \% \mathrm{NaCl}-\mathrm{HI}$ agar plate containing $10 \%$ sucrose was performed to select clones that experienced the second homologous recombination events forcing excision of the vector sequence and leaving only mutated or wild type allele of the genes. Each in-frame deletion mutation was confirmed 
by PCR with the chromosomal DNA from the respective mutant as template. The resulting mutant strains are enlisted in Table 1.

\section{COMPLEMENTATION OF MUTANTS}

For complementation of the mutants, DNA fragments containing wild type genes with respective promoters were amplified using primers listed in Table 2. Amplified DNA fragments were cloned into pCR2.1 TOPO vector (Invitrogen). Fragments containing genes were cut out by appropriate REs and subcloned into the broad host range vector pLAFR3II (Kim et al., 2003). The resulting plasmids were transferred into the mutant strains by the triparental mating using a conjugative helper plasmid pRK2013 (Ditta et al., 1980). The transconjugants were screened on TCBS agar plates containing appropriate antibiotics and confirmed by PCR.

\section{RNA EXTRACTION AND REVERSE TRANSCRIPTION (RT-PCR)}

Total RNA from log phase $V$. vulnificus was extracted using RNeasy mini kit (QIAGEN, Germany) in accordance with the manufacturers' protocol. The quality of RNA was assessed using the NanoDrop ND-1000 spectrophotometer (Thermo Fisher Scientific, USA). The cDNA (from total RNA; $1 \mu \mathrm{g} /$ reaction mixture) was synthesized with the QuantiTect ${ }^{\circledR}$ Reverse Transcription Kit (Qiagen) according to manufacturer's instructions. $0.5 \mu \mathrm{L}$ of cDNA was used in each PCR reaction. Primers used for RT-PCR are listed in Table 2. Fragments were resolved by electrophoresis on $1 \%$ agarose gel.

\section{In vitro SALICYLATE (SA) MEASUREMENT}

SA produced in culture supernatants was determined as previously described (Meyer et al., 1992; Leeman et al., 1996). In brief, $\mathrm{V}$. vulnificus strains were grown in Tris-HCl-buffered minimal medium (100 mM pH 7.5, $1.1 \mathrm{~g} \mathrm{NH}_{4} \mathrm{Cl}, 0.27 \mathrm{~g} \mathrm{KH}_{2} \mathrm{PO}_{4}$, $25 \mathrm{~g} \mathrm{NaCl}, 4 \mathrm{~g}$ succinate, $2 \mathrm{~g}$ casamino acids/L) at $37^{\circ} \mathrm{C}$ for $24 \mathrm{~h}$. Cells were removed by centrifugation and culture supernatants were acidified with $1 \mathrm{~N} \mathrm{HCl}$ to $\mathrm{pH} 2.0$ and SA was extracted into $\mathrm{CHCl}_{3}$ by vigorous shaking (culture supernatant: $\mathrm{CHCl}_{3} ; 3: 1$ ). For quantitative measurements, 1 volume of $2.5 \mathrm{mM} \mathrm{FeCl}_{3}$ was added to the $\mathrm{CHCl}_{3}$ phase. The absorbance of purple Fe-SA complex developed in the aqueous phase was measured at $527 \mathrm{~nm}$ and quantified against a standard of SA dissolved in the same growth medium.

\section{DETECTION OF CATECHOL SIDEROPHORE PRODUCTION}

Siderophore production was detected in bacterial cultures grown in $2.5 \% \mathrm{NaCl}-\mathrm{HI}$ broth or CM9 minimal medium $(0.4 \%$ glucose, $0.2 \%$ sodium succinate, $10 \mathrm{mg} / \mathrm{L}$ glutamate, $\left.0.1 \mu \mathrm{M} \mathrm{FeCl}_{3}\right)$. Overnight grown bacterial cultures were washed in PBS and subcultured into $2.5 \% \mathrm{NaCl}-\mathrm{HI}$ supplemented with DP, or CM9. Siderophore production was quantified by the Arnow test (Arnow, 1937). Briefly, $0.2 \mathrm{ml}$ of culture supernatant, $0.2 \mathrm{ml}$ of $0.5 \mathrm{~N} \mathrm{HCl}$ and $0.2 \mathrm{ml} \mathrm{NaNO}-\mathrm{Na}_{2} \mathrm{MoO}_{4} \cdot 2 \mathrm{H}_{2} \mathrm{O}$ was mixed. After the formation of yellow color, $0.2 \mathrm{ml}$ of $1 \mathrm{~N} \mathrm{NaOH}$ was added resulting in the generation of red color. Total volume was brought to $1 \mathrm{ml}$ with distilled water and the absorbance was measured at $510 \mathrm{~nm}$ using 2,3-DHBA dissolved in the growth medium as standard. DP was assessed not to interfere with the Arnow test. Siderophore concentration was normalized to bacterial cell density $\left(\mu \mathrm{M} / \mathrm{OD}_{600}\right)$.

\section{PRODUCTION, PURIFICATION AND CHARACTERIZATION OF AMP LIGASE RECOMBINANT PROTEINS}

VV2_0836 and VV2_0840 encoding putative AMP ligases were amplified from $V$. vulnificus CMCP6 genomic DNA and cloned into the plasmid pTYB12 (New England Biolabs, Inc.). Amplified DNA fragments were sequenced by the dideoxy-chain termination method (Macrogen Inc., South Korea). Resulted plasmids were transformed into electrocompetent E. coli ER2566 (New England Biolabs, Beverly, MA) using the E.coli Pulsar (BioRad Inc.), for protein expression. Proteins were purified from IPTG induced $(0.4 \mathrm{mM})$ transformed E. coli ER2566 after sonication (Sonics \& Materials Inc. UK, Ltd.), by affinity chromatography using IMPACT ${ }^{\mathrm{TM}}-\mathrm{CN}$ Protein Purification System (New England Biolabs). The purity of recombinant proteins was confirmed by sodium dodecyl sulfate-polyacrylamide gel electrophoresis (SDSPAGE). The concentration of the obtained proteins was determined by Quick Start ${ }^{\mathrm{TM}} 1 \times$ Bradford dye (Bio-Rad Laboratories) and purified proteins were stored at $-80^{\circ} \mathrm{C}$ in stock buffer (25 mM Tris, pH 8.0, $10 \mathrm{mM} \mathrm{MgCl}_{2}, 5 \mathrm{mM} \mathrm{DTT}$, and $10 \%$ glycerol).

AMP ligase activity of purified recombinant protein was determined by measuring the pyrophosphate release (Rusnak et al., 1989). This reaction was coupled with the pyrophosphatase reaction. Reaction mixtures (total volume: $100 \mu \mathrm{L}$ ) containing $1 \mu \mathrm{M}$ of VV2_0836 or VV2_0840 recombinant proteins, 0.2 unit of $E$. coli inorganic pyrophosphatase (Sigma), $75 \mathrm{mM}$ Tris ( $\mathrm{pH} 7.5$ ), $10 \mathrm{mM} \mathrm{MgCl}_{2}, 1.5 \mathrm{mM}$ ATP, $5 \mathrm{mM}$ DTT, and $0.6 \mathrm{mM}$ salicylate (Junsei) or 2, 3-DHBA (Sigma) were incubated at $37^{\circ} \mathrm{C}$. The amount of inorganic phosphate $(\mathrm{Pi})$ produced in the reaction mixture was assayed by measuring the chromophore generated after mixing with an ammonium molybdate-malachite green solution at $620 \mathrm{~nm}$ (Sousa et al., 2006; Khalil and Pawelek, 2011).

\section{DETERMINATION OF LD $_{50}$ IN MICE}

The $\mathrm{LD}_{50}$ of mutants to mice was determined by our previously described method (Kim et al., 2008). Briefly, 7-weekold specific pathogen-free (SPF) randomly bred ICR female mice (5 mice/group) were inoculated intraperitoneally with 10 fold serial dilutions of test strains $\left(10^{9}-10^{5} \mathrm{cfu} / \mathrm{mouse}\right)$. Deaths were observed for $48 \mathrm{~h}$ and $\mathrm{LD}_{50}$ values were calculated by the method of Reed and Muench (1938). All animal experiments were approved by the Animal Care and Use Committee of Chonnam National University, South Korea.

\section{STATISTICAL ANALYSIS}

Statistical significance of the growth differences at each time point and differences in siderophore production between strains were compared using the Student's $t$-test. $P$-values less than 0.05 were considered statistically significant. Statistical values were calculated using GraphPad Prism 5 or Microsoft Excel, wherever appropriate. All experiments were repeated three times in triplicates, and results from representative experiments are shown. 


\section{RESULTS}

EXPRESSION OF VV2_0834, VV2_0839, VV2_0836, AND VV2_0840 IS INDUCED BY IRON-LIMITATIONS AND IS UNDER THE CONTROL OF FUR

To investigate the effect of iron levels on the expression of selected target genes, total RNA was extracted from wild type CMCP6 cultured in $2.5 \% \mathrm{NaCl}-\mathrm{HI}$ supplemented with various amounts of DP. Expression of target genes could not be detected in iron sufficient conditions (Figure 1B). However, expression of VV2_0839 could be detected when DP was added to a final concentration of $50 \mu \mathrm{M}$, while that of other three genes could be detected at $75 \mu \mathrm{M}$ DP concentration (Figure 1B). Fur (ferric uptake regulator) is the global regulator of iron acquisition system (Escolar et al., 1999; Panina et al., 2001). To confirm the regulatory effect of Fur, we developed a Fur deletion mutant of $V$. vulnificus and checked the expression of the four selected genes in this mutant grown in 2.5\% $\mathrm{NaCl}-\mathrm{HI}$ without any DP (Figure 1B). The expression of these four genes was found to be upregulated in the mutant suggesting that Fur acted as a repressor for expression of these four genes under iron-rich conditions.

\section{SA IS DISPENSABLE WHILE 2, 3-DHBA IS ESSENTIAL FOR $\boldsymbol{V}$. vulnificus GROWTH UNDER IRON-LIMITED CONDITIONS}

The siderophore vulnibactin had been reported to contain one residue of 2, 3-DHBA and two residues of SA (Okujo et al., 1994). To investigate the importance of these two substrates for siderophore assembly, mutants with in-frame deletions of respective synthesis genes (VV2_0834 and VV2_0839) were constructed. The growth of mutants was estimated in iron-limited conditions. Against our expectations, $\Delta 20839$ mutant showed only a slight growth defect $(P>0.05)$ (Figures 2A,B), despite SA being a major building block of vulnibactin. To confirm the function of the gene VV2_0839, SA production in $\Delta 20839$ mutant was measured. No SA production was observed in $\Delta 20839$ mutant (Figure 2E).

Under $140 \mu \mathrm{M}$ DP condition, $\Delta 20834$ exhibited initial significantly retarded growth $(P<0.01,9 \mathrm{~h}$ time point) followed by an increased growth rate, ultimately catching up with the wild type strain (Figure 2A). However, the same mutant could not catch up the growth if the DP concentration was increased to $150 \mu \mathrm{M}$ (Figure 2B). The double mutant $(\Delta 20839 / 20834)$ manifested more profound growth defect than single gene mutants under both 140 and $150 \mu \mathrm{M}$ DP conditions. These results clearly suggest that though VV2_0839 is essential for SA synthesis but SA itself is dispensable, while 2, 3-DHBA is essential for the vulnibactin-dependent growth of bacterium under iron-limited conditions. More importantly, these results suggest that vulnibactin, composed of two SA and one 2, 3-DHBA may not to be the only type of siderophore secreted by $V$. vulnificus in response to iron-limitations.

\section{CATECHOL SIDEROPHORE PRODUCTION IS IMPEDED BY THE MUTATION OF VV2_0834 AND VV2_0839}

To further ascertain the importance of genes responsible for biosynthesis of the catechol siderophore in $V$. vulnificus, levels of siderophore production in mutants were measured by the Arnow test (Arnow, 1937). In 2.5\% NaCl-HI broth supplemented with 140 or $150 \mu \mathrm{M}$ DP, more catechol siderophore was secreted

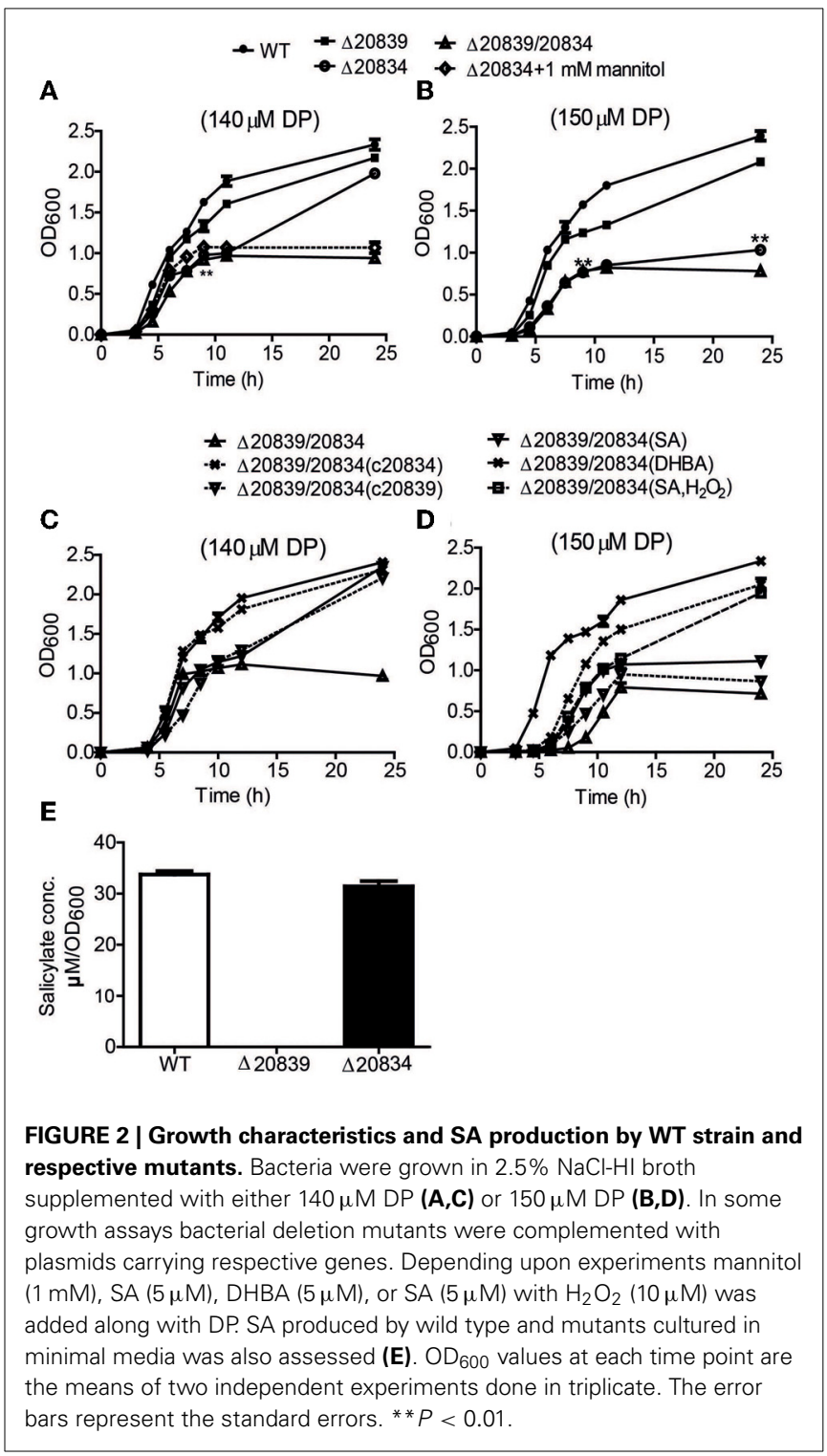

by the $\Delta 20839$ mutant than the wild type strain (Figure 3A). But in minimal medium, no siderophore was detected in the culture supernatant of $\Delta 20839$ (Figure 3C) even though this mutant showed same growth levels as wild type (Figure 3C, satellite) suggesting the presence of an alternate siderophore composed solely of 2, 3-DHBA, produced in iron limited HI broth but not in minimal medium. However, results indicated that the siderophore synthesized without SA was less efficient in acquiring iron since the $\Delta 20839$ mutant was slightly impeded compared with wild type despite a higher level of siderophore produced in the culture. Interestingly, we found that $\Delta 20834$ mutant was capable of secreting catechol siderophore in $2.5 \%$ $\mathrm{NaCl}-\mathrm{HI}$ supplemented with $140 \mu \mathrm{M}$ DP, and that siderophore was accumulated in the late growth stage (Figure 3A). The accumulated siderophore in the later growth phase seems to be responsible for the catch-up growth of the mutant (Figure 2A). Though the siderophore amount produced by the single mutant 


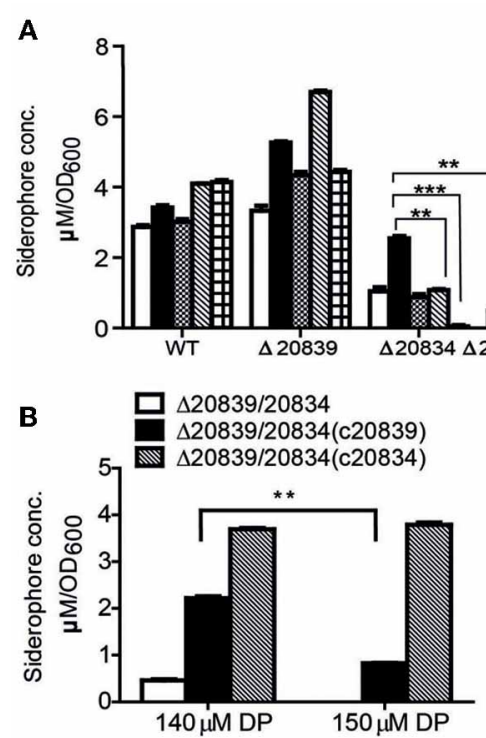

FIGURE 3 | Siderophore production measurement by Arnow test. (A) WT and mutants were grown in $2.5 \% \mathrm{NaCl}-\mathrm{HI}$ supplemented with 140 or $150 \mu \mathrm{M}$ DP for 9 or $24 \mathrm{~h}$. In some experiments mannitol (1 $\mathrm{mM}$ ) was added along with DP. (B) Siderophore levels produced by double mutant and its single gene complemented strains grown in $2.5 \% \mathrm{NaCl}-\mathrm{HI}$ with added DP. (C)

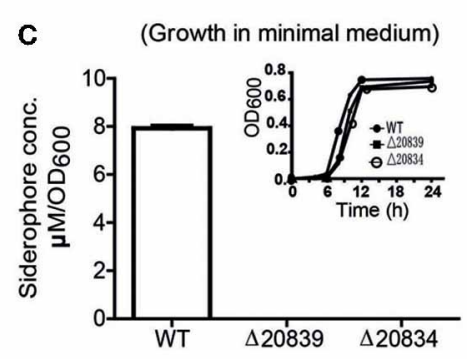

Siderophore levels produced by WT or single gene mutants grown in minimal medium. Satellite graph represents the growth profile of respective bacterial strains in minimal medium. Siderophore concentration was normalized to cell density: concentration $(\mu \mathrm{M}) / \mathrm{OD}_{600}$ of cell culture. Error bars represent standard error of mean $(n=3) .{ }^{* *} P<0.01,{ }^{* * *} P<0.0001$. was less than that secreted by wild type, it was significantly higher than that secreted by the double mutant $(\Delta 20839 / 20834)$ (Figure 3A). However, the siderophore production in $2.5 \%$ $\mathrm{NaCl}-\mathrm{HI}$ with $150 \mu \mathrm{M}$ DP and minimal medium was nearly abolished in both single and double mutants $(\Delta 20839 / 20834)$ (Figures 3A,C) indicating that somehow SA contributed to the later growth stage production of catechol siderophore in $\Delta 20834$ mutant.

\section{HYDROXYL RADICALS FACILITATE THE PRODUCTION OF 2, 3-DHBA FROM SA IN VV2_0834 MUTANT ( $\Delta$ 20834)}

During stationary growth phase, bacterial cells experience stressful conditions such as decreased $\mathrm{pH}$ or increased ROS in culture medium (Storz and Imlay, 1999; Poole, 2012). It has been previously reported that in the presence of free hydroxyl radicals SA is chemically converted to catechol acid, 2, 3-DHBA and 2, 5-DHBA (Grootveld and Halliwell, 1986). Thus, we presumed that SA produced by the $\Delta 20834$ mutant could have been attacked by ROS-derived hydroxyl radicals, which consequently lead to the formation of 2, 3-DHBA used for the ultimate production of vulnibactin during the observed late stage catch-up growth (Figure 2A). Mannitol has been shown to be an effective quencher of hydroxyl radicals, inhibiting the production of 2, 3-DHBA from SA (Wendel, 1987). To confirm our hypothesis that SA was being converted to 2, 3DHBA, we grew the $\Delta 20834$ mutant in the presence of various concentrations of mannitol and found that $1 \mathrm{mM}$ mannitol inhibited the late stage growth of $\Delta 20834$ mutant (Figure 2A). These results were further corroborated by measuring catechol siderophore production in $\Delta 20834$ mutant after mannitol supplementation. Compared to no mannitol condition, siderophore production in the $\Delta 20834$ mutant was significantly impeded in the presence of mannitol (Figure 3A). These results conclusively point toward the possibility of SA hydroxylation by free hydroxyl radicals.

\section{SA OR 2, 3-DHBA CAN RESTORE THE DEFECT OF $\Delta 20839 / 20834$ DOUBLE MUTANT}

To further confirm the role SA and 2, 3-DHBA in the vulnibactin biosynthesis, we supplied the double mutant $\Delta 20839 / 20834$ with either SA or 2, 3-DHBA and observed the growth profile in iron-limited 2.5\% NaCl-HI. As expected, 2, 3-DHBA fully restored the growth of double mutant in iron-limited conditions regardless of DP concentration (Figures 2C,D). However, SA could rescue the growth of double mutant in iron-limited condition till $140 \mu \mathrm{M}$ DP concentration showing a growth profile similar to the $\Delta 20834$ mutant under $140 \mu \mathrm{M}$ DP condition (Figures 2A,C). If the concentration of DP was increased to $150 \mu \mathrm{M}, \mathrm{SA}$ alone could not rescue the growth defect of double mutant that could however be rescued in presence of $\mathrm{H}_{2} \mathrm{O}_{2}$ (Figure 2D). Considering that the generation of hydroxyl radical would be dependent upon iron availability and bacterial growth, it is likely that self-generated hydroxyl radicals from the double mutant were not sufficient to hydroxylate SA to 2, 3 -DHBA for supporting mutant growth in $150 \mu \mathrm{M}$ DP condition. Growth patterns similar to that obtained after SA or 2, 3DHBA supplementation of double mutant $(\Delta 20839 / 20834)$ were obtained after complementation with either gene i.e., VV2_0839 or VV2_0834 (Figures 2C,D). Moreover the decrease pattern of siderophore in the presence of DP (Figure 3A) was similar to that observed with respective single deletion mutants (Figure 3B). 


\section{ACTIVITY OF AMP LIGASES IS AFFECTED BY IRON LEVEL}

In the siderophore biosynthetic gene cluster, two genes (VV2_0836 and VV2_0840) encode putative AMP ligases for activation of 2, 3-DHBA and initiating siderophore assembly (Khalil and Pawelek, 2011). Their amino acid sequences showed $42 \%$ similarity. To characterize the roles played by these two genes in the siderophore synthesis, in-frame deletion mutants of these genes were constructed and growth was tested under iron-limited conditions. The single gene mutant $\Delta 20840$ showed more severe growth defect at only higher DP concentrations while growth of the $\Delta 20836$ strain was significantly retarded even at lower concentrations of DP (Figures 4A-C) indicating a more dominant role played by VV2_0836 in vulnibactin assembly. As expected, the growth of double mutant $\Delta 20836 / 20840$ was significantly retarded by iron limitation that nonetheless could be restored fully by complementation with VV2_0836 till at least $150 \mu \mathrm{M}$ DP condition, while only partially when complemented with VV2_0840 (Figure 4B). In $160 \mu \mathrm{M}$ DP condition, the growth of double mutant could not be restored by either of the genes while growth defect of single gene mutants could be restored completely by respective gene complementation (Figure 4C). These results clearly indicate the essentiality of two AMP ligases for the siderophore biosynthesis under extremely iron-limited conditions.

\section{TWO AMP LIGASES CAN ACTIVATE 2, 3-DHBA AND SA}

To investigate the substrate specificity of two AMP ligases, we cloned the two genes (VV2_0836 and VV2_0840) into the expression vector pTYB12. Recombinant proteins were purified
(Figure 5A) and tested for enzymatic activities with SA or 2, 3-DHBA as substrate. The AMP ligase reaction was assayed spectrophotometrically by coupling the formation of PPi to pyrophosphatase reactions. The generation velocity of Pi indicated the efficiency of AMP ligase. Results indicated that though both AMP ligases could act on 2, 3-DHBA and SA (Figure 5B) but AMP ligase encoded by VV2_0836 had higher enzymatic activity than that by VV2_0840. These results further indicate that SA might be the optimal substrate for AMP ligase encoded by VV2_0836 since its action on SA was much prompt $(P<0.01)$ and significantly higher $(P<0.0001)$ than on 2,3 -DHBA.

\section{VV2 0839 IS THE MAJOR CONTRIBUTOR TO MOUSE LETHALITY}

As shown in Table 3, mutation of either of the two AMP ligases (VV2_0836 or VV2_0840) resulted in a marginal 2-fold increase in $\mathrm{LD}_{50}$ compared to that of wild type strain. However, as expected, $\mathrm{LD}_{50}$ of double mutant $\Delta 20836 / 20840$ increased by 10 -fold indicating an important synergistic contribution made by both AMP ligases toward virulence to mice, at least through intraperitoneal route. However, deletion of VV2_0839 or VV2_0834 gene resulted in an increase in $\mathrm{LD}_{50}$ by 137 and 2 -fold respectively suggesting that SA played a more important role in virulence than 2, 3-DHBA. Considering 10-fold increase in $\mathrm{LD}_{50}$ by mutation of both AMP ligases, we could speculate that the significantly impaired virulence of $\Delta 20839$ mutant should not solely be due to the defect in the siderophore biosynthesis and SA might play physiological role through other yet unidentified mechanisms warranting the estimation of pathophysiological significance of SA synthesis in future studies.
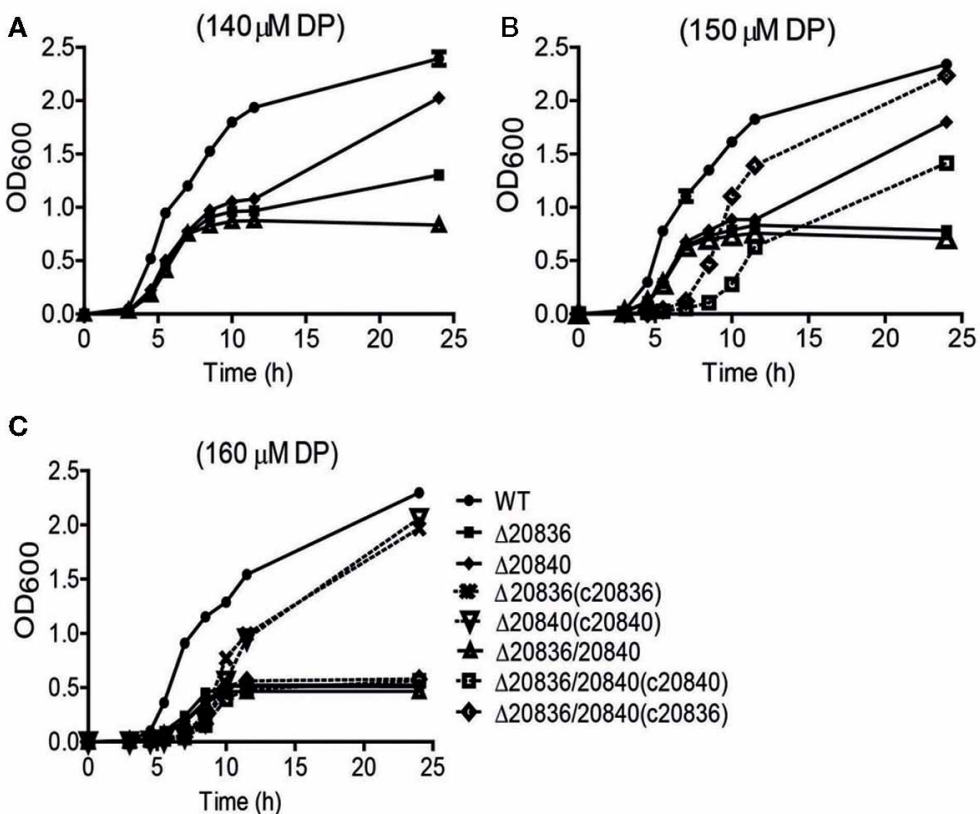

FIGURE 4 | Growth characteristics of wild-type $V$. vulnificus CMCP6 and various AMP ligase gene mutants under iron-limited conditions. WT, $\Delta 20836, \Delta 20840, \Delta 20836 / 20840$, and complemented strains were grown in $2.5 \% \mathrm{NaCl}-\mathrm{HI}$ broth with added $140 \mu \mathrm{M}$ (A), $150 \mu \mathrm{M}$ (B), or $160 \mu \mathrm{M}$ DP (C). $\mathrm{OD}_{600}$ value at each time point represents the mean of two independent cultures of each strain tested, and the error bars represent the standard error of mean. 


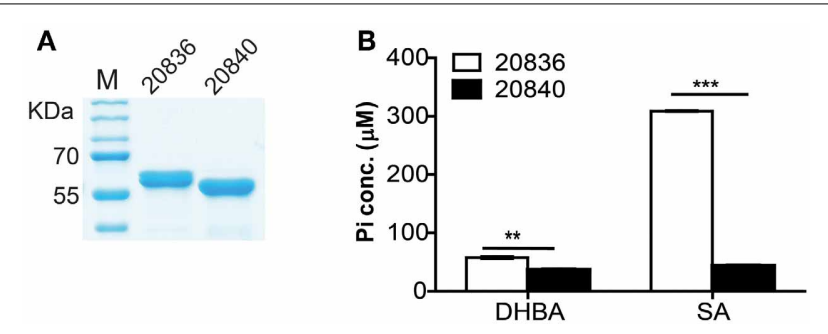

FIGURE 5 | Purity of the two AMP ligases (A) and their respective activities after $12 \mathrm{~min}$ of incubation with 2, 3-DHBA or SA as enzyme substrates (B). AMP ligase reaction was assayed spectrophotometrically by coupling the formation of PPi (inorganic pyrophosphate) to the pyrophosphatase reactions. The substrate specificity of the two AMP ligases was tested by measuring the formation of inorganic phosphate (Pi). At each time point error bars represent standard errors of mean $(n=3)$. ** $P<0.01,{ }^{* * *} P<0.0001$.

Table 3 | Effect of the mutation on the lethality to mice.

\begin{tabular}{lcc}
\hline Strain & Intraperitoneal LD $_{\mathbf{5 0}}$ (CFU/mouse) & Fold increase \\
\hline Wild type & $4.0 \times 10^{5}$ & 1.0 \\
$\Delta 20834$ & $8.7 \times 10^{5}$ & 2.1 \\
$\Delta 20839$ & $5.5 \times 10^{7}$ & 137 \\
$\Delta 20839 / 20834$ & $5.5 \times 10^{7}$ & 137 \\
$\Delta 20836$ & $7.4 \times 10^{5}$ & 1.85 \\
$\Delta 20840$ & $8.9 \times 10^{5}$ & 2.22 \\
$\Delta 20836 / 20840$ & $4.0 \times 10^{6}$ & 10 \\
\hline
\end{tabular}

\section{DISCUSSION}

The importance of iron for pathogenicity of $V$. vulnificus has been demonstrated both clinically and experimentally (Wright et al., 1981; Gulig et al., 2005). Siderophores mediate efficient iron uptake in most bacteria. It was reported that $V$. vulnificus produces a catechol-like siderophore called vulnibactin (Simpson and Oliver, 1983). Genes supposed to be involved in vulnibactin biosynthesis are clustered at a locus of chromosome 2 of $\mathrm{V}$. vulnificus. We analyzed the transcriptome of this bacterium using rat peritoneal cavity infection model (Rhee, unpublished study) and found that genes in the aforementioned cluster were highly up-regulated in vivo. In the present study, the RT-PCR results showed that iron concentration tightly regulated the expression of selected target genes (VV2_0834, VV2_0839, VV2_0836, and VV2_0840) in this gene cluster. Expression of these genes was not detected in iron-sufficient conditions and could only be found after iron depletion by DP. Expression of each gene was initiated at different DP concentration. Fur is the global regulator of iron acquisition systems (Escolar et al., 1999). Up regulation of these four genes upon deletion of Fur suggested the repressor function of the regulator. However, we also observed expression of these genes in iron rich $0.9 \% \mathrm{NaCl}-\mathrm{HI}$ (data not shown); suggesting that Fur might not be the only regulator of these four genes as these might also be influenced by osmolarity sensing system. In this regard, siderophore genes may also be under the regulation of other global regulators in vivo.
In this study, we showed that deletion of VV2_0839 abolished SA production and by extension siderophore production in minimal medium, but in iron-limited nutritious conditions higher amount of siderophore was produced suggesting that SA is dispensable for at least growth of bacterium in nutrition rich conditions as the mutant $\Delta 20839$ exhibited insignificant growth defect in HI medium. The chemical structure of vulnibactin was identified to contain one residue of 2, 3-DHBA and two residues of SA and was found to be closely related to that of vibriobactin, a type of catechol siderophore secreted by V. cholerae (Griffiths et al., 1984). It is likely that there is an alternative type of siderophore produced by $V$. vulnificus, composed solely of 2,3-DHBA. However, the iron-sequestering activity of the alternative siderophore seemed to be weaker than vulnibactin (Figures 2A,B). Though for better conclusion of these observations future investigations regarding exact extraction and chemical characterization of siderophores would be required.

We found that the growth characteristics of $\Delta 20834$ mutant were tightly associated with the concentration of supplemented DP, hence the available iron levels. In HI with $140 \mu \mathrm{M}$ or lower DP concentrations, growth of $\Delta 20834$ mutant exhibited a stepwise pattern (Figure 2A) having a retarded early growth stage, short stable stage and the late growth stage catching up ultimately with the wild type. The late growth stage of $\Delta 20834$ mutant could be inhibited by increasing the DP concentration to $150 \mu \mathrm{M}$, by addition of hydroxyl radical scavenger mannitol, or by additional deletion of VV2_0839. SA itself is capable of scavenging reactive hydroxyl radicals $(\cdot \mathrm{OH})$ (Wendel, 1987) leading to the generation of catechol acid, 2, 3-DHBA and 2, 5-DHBA (Grootveld and Halliwell, 1986). In bacterial cultures, hydroxyl radicals could be generated from bacterial respiration or from Fenton reaction. We observed that the $\mathrm{pH}$ of culture medium of the $\Delta 20834$ mutant fell from 7 to 6 after $9 \mathrm{~h}$ of growth in $140 \mu \mathrm{M}$ DP condition. Hydroxylation of SA is favored in acidic $\mathrm{pH}$ resulting in higher conversion rates of SA to 2, 3-DHBA (Chakinala et al., 2007), explaining the stepwise growth pattern of $\Delta 20834$ mutant and ultimately reaching the growth profile of the wild type. From these data, we could conclude that SA was used as a scavenger of hydroxyl radicals protecting the bacteria from reactive oxygen species, and also supplying 2, 3-DHBA for siderophore biosynthesis. The complementation results and growth restoration by 2 , 3-DHBA, SA, or SA with $\mathrm{H}_{2} \mathrm{O}_{2}$ further substantiated the hypothesis that SA was being converted to 2, 3-DHBA leading to the formation of vulnibactin even in the absence of VV2_0834. These results also emphasized the essentiality of 2, 3-DHBA for bacterial growth in iron-limited conditions.

In the siderophore biosynthetic gene cluster, we found two genes encoding putative AMP ligases. Previously it has been predicted that the residues in the carboxyl acid binding pocket of AMP ligase help in discriminating between 2, 3-DHBA and SA (May et al., 2002). By alignment, the AMP ligase encoded by VV2_0836 was more likely to act on 2, 3-DHBA, while the AMP ligase encoded by VV2_0840 was more likely to act on SA. However, our in vitro enzymatic activity test results showed that both of AMP ligases were capable of acting on 2, 3-DHBA and SA. Moreover, AMP ligase encoded by VV2_0836 exhibited much higher activity on SA than AMP ligase encoded by VV2_0840. 
Both AMP ligases showed relatively low activity on 2, 3-DHBA compared to SA. By measuring the amount of secreted SA and 2, 3-DHBA by the double AMP ligase mutant cultured in the minimal media, we found more SA was accumulated than 2, 3-DHBA (data not shown). It is likely that $V$. vulnificus divide more chorismate for SA production than 2, 3-DHBA. For the growth under iron-limited conditions, VV2_0836 encoded AMP ligase appeared to be more important than VV2_0840 AMP ligase, except that both are required for growth in extremely ironlimited conditions. However, the mechanism through which iron influences the essentiality of AMP ligases remains unclear.

To assess the role of the four genes in the virulence of $V$. vulnificus, we determined the $\mathrm{LD}_{50}$ of mutants to ICR female mice. $\mathrm{LD}_{50}$ of $\Delta 20839$ was significantly higher than $\Delta 20834$. Our transcriptome analysis showed that in vivo expression of gene VV2_0839 was up-regulated 187-fold compared with in vitro culture, while 96-fold for VV2_0834, suggesting a more important role of SA in pathogenicity of $V$. vulnificus than 2, 3-DHBA. In this study, we observed that SA was scavenging the hydroxyl ions in vitro, and was capable of supplying 2, 3-DHBA for siderophore biosynthesis. Thus, it seems possible that $V$. vulnificus secrets SA for not only siderophore synthesis but also for protecting the bacterium from damage caused by hydroxyl radicals generated in vivo. Another interesting possibility for in vivo SA synthesis comes from the fact that SA possesses anti-inflammatory properties. There are a number of reports showing that SA interferes with intracellular signaling pathways such as protein-kinases (MAPK) cascade (Wang and Brecher, 1999) and NF-kB pathway (Kopp and Ghosh, 1994) and may diminish the host inflammatory response to the pathogen. However, this possibility remains to be verified by in appropriate animal model studies.

Taken together, in this study we addressed the important role of 2, 3-DHBA, SA and two AMP ligases for siderophore biosynthesis. Based upon the data obtained from the present study, we constructed a vulnibactin biosynthesis pathway map that is slightly different from that has been predicted in the KEGG database (http://www.genome.jp/kegg-bin/showpathway? vvu01053+VV20834). According to our proposed vulnibactin

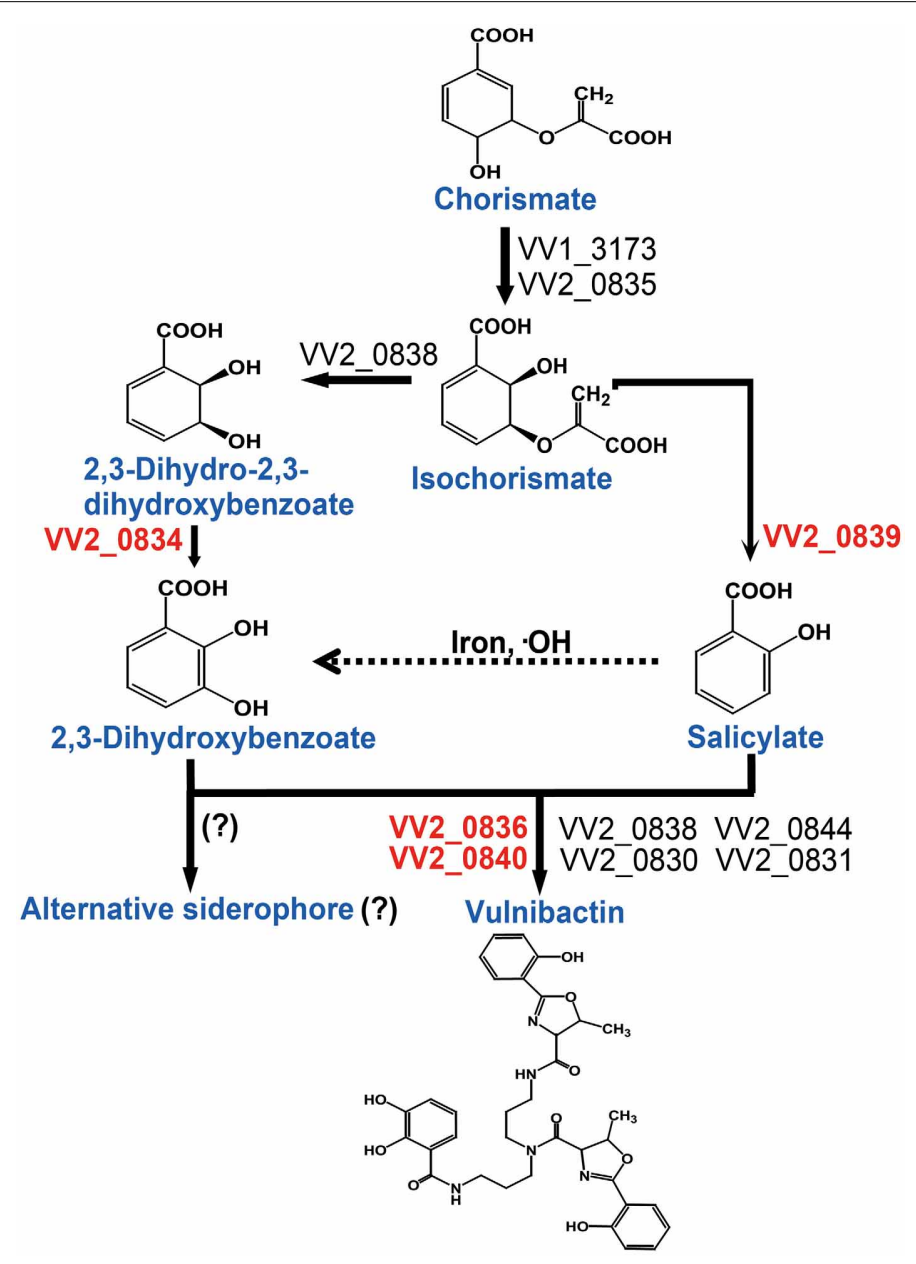

FIGURE 6 | Proposed vulnibactin biosynthesis pathway in $\mathbf{V}$. vulnificus. 2, 3-DHBA and SA are synthesized from the common precursor chorismate and are activated by AMP ligases encoded by VV2_0836 and VV2_0840 for siderophore assembly. In presence of iron and hydroxyl radicals SA can be non-enzymatically converted to 2, 3-DHBA (dashed arrow) that then may be routed to synthesis of a yet unidentified siderophore composed solely of 2 , 3-DHBA. Question marks (?) represent the fact that identity of the reaction or the alternate siderophore is yet to be established. 
biosynthetic pathway (Figure 6) isochorismate may be routed to 2, 3-DHBA or SA synthesis, mediated by specific enzymes (VV_20834 and VV_20839 respectively). Synthesized 2, 3-DHBA and SA are assembled into vulnibactin by two AMP ligases (VV2_0836 and VV2_0840). Moreover, SA in presence of hydroxyl radicals may be non-enzymatically converted to 2, 3-DHBA that may be utilized for the production of yet unidentified alternative siderophore that, like vibriobactin, may be composed solely of 2,3-DHBA. Hence, it is intriguing to suggest that the type and quantity of siderophore synthesized would be determined by the environmental cues sensed by this opportunistic pathogen. We further suggest that SA in V. vulnificus serves as a scavenger of hydroxyl radicals and plays an importance role in the virulence of V. vulnificus. However, there are several unanswered questions such as exact contribution of SA and vulnibactin, not only as a virulence factor but also as a bacterial defense mechanism to evade host innate inflammatory responses, besides contribution of in vivo activated global regulators in siderophore synthesis that needs further exploration.

\section{ACKNOWLEDGMENTS}

Joon Haeng Rhee was supported by a grant from the Regional Technology Innovation Program of the Ministry of Knowledge Economy of the Republic of Korea (No. RTI 05-01-01). Shee Eun Lee was supported by an NRF grant from the MSIP (2013R1A2A2A01005011). Wenzhi Tan was supported by the BK21 Plus (Brain Korea 21) Program for Leading Universities and Students, Ministry of Education, Republic of Korea.

\section{REFERENCES}

Arnow, L. E. (1937). Colorimetric determination of the compounds of 3,4dihydroxyphenyl-alanine tyrosine mixtures. J. Biol. Chem. 118, 531-537.

Braun, V., and Killmann, H. (1999). Bacterial solutions to the iron-supply problem. Trends Biochem. Sci. 24, 104-109. doi: 10.1016/S0968-0004(99)01359-6

Chakinala, A. G., Gogate, P. R., Burgess, A. E., and Bremner, D. H. (2007). Intensification of hydroxyl radical production in sonochemical reactors. Ultrason. Sonochem. 14, 509-514. doi: 10.1016/j.ultsonch.2006.09.001

Chang, C. Y., Hsieh, Y. H., Cheng, K. Y., Hsieh, L. L., Cheng, T. C., and Yao, K. S. (2008). Effect of $\mathrm{pH}$ on Fenton process using estimation of hydroxyl radical with salicylic acid as trapping reagent. Water Sci. Technol. 58, 873-879. doi: 10.2166/wst.2008.429

Ditta, G., Stanfield, S., Corbin, D., and Helinski, D. R. (1980). Broad host range DNA cloning system for gram-negative bacteria: construction of a gene bank of Rhizobium meliloti. Proc. Natl. Acad. Sci. U.S.A. 77, 7347-7351. doi: 10.1073/pnas.77.12.7347

Escolar, L., Perez-Martin, J., and De Lorenzo, V. (1999). Opening the iron box: transcriptional metalloregulation by the fur protein. J. Bacteriol. 181, 6223-6229.

Gaille, C., Kast, P., and Haas, D. (2002). Salicylate Biosynthesis in Pseudomonas aeruginosa: purification and characterization of $\mathrm{PchB}$, a novel bifunctional enzyme displaying isochorismate pyruvate-lyase and chorismate mutase activities. J. Biol. Chem. 277, 21768-21775. doi: 10.1074/jbc.M202410200

Gaille, C., Reimmann, C., and Haas, D. (2003). Isochorismate Synthase (PchA), the First and Rate-limiting Enzyme in Salicylate Biosynthesis of Pseudomonas aeruginosa. J. Biol. Chem. 278, 16893-16898. doi: 10.1074/jbc.M212324200

Griffiths, G. L., Sigel, S. P., Payne, S. M., and Neilands, J. B. (1984). Vibriobactin, a siderophore from Vibrio cholerae. J. Biol. Chem. 259, 383-385.

Grootveld, M., and Halliwell, B. (1986). Aromatic hydroxylation as a potential measure of hydroxyl-radical formation in vivo. Identification of hydroxylated derivatives of salicylate in human body fluids. Biochem. J. 237, 499-504.

Gulig, P. A., Bourdage, K. L., and Starks, A. M. (2005). Molecular Pathogenesis of Vibrio vulnificus. J. Microbiol. 43, 118-131.
Halliwell, B., Hoult, J. R., and Blake, D. R. (1988). Oxidants, inflammation, and anti-inflammatory drugs. FASEB J. 2, 2867-2873.

Hiller, K. O., Hodd, P. L., and Willson, R. L. (1983). Antiinflammatory drugs: protection of a bacterial virus as an in vitro biological measure of free radical activity. Chem. Biol. Interact. 47, 293-305. doi: 10.1016/0009-2797(83) 90165-5

Horton, R. M., Hunt, H. D., Ho, S. N., Pullen, J. K., and Pease, L. R. (1989). Engineering hybrid genes without the use of restriction enzymes: gene splicing by overlap extension. Gene 77, 61-68. doi: 10.1016/0378-1119(89) 90359-4

Keating, T. A., Marshall, C. G., and Walsh, C. T. (2000). Reconstitution and characterization of the Vibrio cholerae vibriobactin synthetase from VibB, VibE, VibF, and VibH. Biochemistry 39, 15522-15530. doi: 10.1021/bi0016523

Khalil, S., and Pawelek, P. D. (2011). Enzymatic adenylation of 2,3dihydroxybenzoate is enhanced by a protein-protein interaction between Escherichia coli 2,3-dihydro-2,3-dihydroxybenzoate dehydrogenase (EntA) and 2,3-dihydroxybenzoate-AMP ligase (EntE). Biochemistry 50, 533-545. doi: $10.1021 / b i 101558 \mathrm{v}$

Kim, H. U., Kim, S. Y., Jeong, H., Kim, T. Y., Kim, J. J., Choy, H. E., et al. (2011). Integrative genome-scale metabolic analysis of Vibrio vulnificus for drug targeting and discovery. Mol. Syst. Biol. 7, 460. doi: 10.1038/msb.2010.115

Kim, S. Y., Hong, H. Y., Rhee, J. H., and Chung, S. S. (2008). Roles of flagellar hookassociated proteins in Vibrio vulnificus motility and virulence. J. Bacteriol. Virol. 38, 1-10. doi: 10.4167/jbv.2008.38.1.1

Kim, S. Y., Lee, S. E., Kim, Y. R., Kim, C. M., Ryu, P. Y., Choy, H. E., et al. (2003). Regulation of Vibrio vulnificus virulence by the LuxS quorum-sensing system. Mol. Microbiol. 48, 1647-1664. doi: 10.1046/j.1365-2958.2003.03536.x

Kopp, E., and Ghosh, S. (1994). Inhibition of NF-kappa B by sodium salicylate and aspirin. Science 265, 956-959. doi: 10.1126/science.8052854

Leeman, M., Ouden, F. M. D., Pelt, J. A. V., Dirkx, F. P. M., Steijl, H., Bakker, P. A. H. M., et al. (1996). Iron availability affects induction of systemic resistance to fusarium wilt of radish by Pseudomonas fluorescens. Phytopathology 86, 149-155. doi: 10.1094/Phyto-86-149

Litwin, C. M., Rayback, T. W., and Skinner, J. (1996). Role of catechol siderophore synthesis in Vibrio vulnificus virulence. Infect. Immun. 64, 2834-2838.

Liu, J., Duncan, K., and Walsh, C. T. (1989). Nucleotide sequence of a cluster of Escherichia coli enterobactin biosynthesis genes: identification of entA and purification of its product 2,3-dihydro-2,3-dihydroxybenzoate dehydrogenase. J. Bacteriol. 171, 791-798.

Liu, J., Quinn, N., Berchtold, G. A., and Walsh, C. T. (1990). Overexpression, purification, and characterization of isochorismate synthase (EntC), the first enzyme involved in the biosynthesis of enterobactin from chorismate. Biochemistry 29, 1417-1425. doi: 10.1021/bi00458a012

Maskos, Z., Rush, J. D., and Koppenol, W. H. (1990). The hydroxylation of the salicylate anion by a Fenton reaction and T-radiolysis: a consideration of the respective mechanisms. Free Radic. Biol. Med. 8, 153-162. doi: 10.1016/0891$5849(90) 90088-Z$

May, J. J., Kessler, N., Marahiel, M. A., and Stubbs, M. T. (2002). Crystal structure of DhbE, an archetype for aryl acid activating domains of modular nonribosomal peptide synthetases. Proc. Natl. Acad. Sci. U.S.A. 99, 12120-12125. doi: 10.1073/pnas. 182156699

Meyer, J. M., Azelvandre, P., and Georges, C. (1992). Iron metabolism in Pseudomonas: salicylic acid, a siderophore of Pseudomonas fluorescens CHAO. Biofactors 4, 23-27.

Miller, V. L., and Mekalanos, J. J. (1988). A novel suicide vector and its use in construction of insertion mutations: osmoregulation of outer membrane proteins and virulence determinants in Vibrio cholerae requires toxR. J. Bacteriol. 170, 2575-2583.

Milton, D. L., O’Toole, R., Horstedt, P., and Wolf-Watz, H. (1996). Flagellin A is essential for the virulence of Vibrio anguillarum. J. Bacteriol. 178, 1310-1319.

Morris, J. G., Wright, A. C., Simpson, L. M., Wood, P. K., Johnson, D. E., and Oliver, J. D. (1987). Virulence of Vibrio vulnificus: association with utilization of transferrin-bound iron, and lack of correlation with levels of cytotoxin or protease production. FEMS Microbiol. Lett. 40, 55-59. doi: 10.1111/j.15746968.1987.tb01982.x

Nahlik, M. S., Brickman, T. J., Ozenberger, B. A., and Mcintosh, M. A. (1989). Nucleotide sequence and transcriptional organization of the Escherichia coli enterobactin biosynthesis cistrons entB and entA. J. Bacteriol. 171, 784-790. 
Okujo, N., Saito, M., Yamamoto, S., Yoshida, T., Miyoshi, S., and Shinoda, S. (1994). Structure of vulnibactin, a new polyamine-containing siderophore from Vibrio vulnificus. Biometals 7, 109-116. doi: 10.1007/BF00140480

Panina, E. M., Mironov, A. A., and Gelfand, M. S. (2001). Comparative analysis of Fur regulons in gamma-proteobacteria. Nucleic Acids Res. 29, 5195-5206. doi: $10.1093 / \mathrm{nar} / 29.24 .5195$

Poole, K. (2012). Bacterial stress responses as determinants of antimicrobial resistance. J. Antimicrob. Chemother. 67, 2069-2089. doi: 10.1093/jac/dks196

Reed, L. J., and Muench, H. (1938). A simple method for estimating fifty percent end points. Am. J. Epidemiol. 27, 493-497.

Rusnak, F., Faraci, W. S., and Walsh, C. T. (1989). Subcloning, expression, and purification of the enterobactin biosynthetic enzyme 2,3-dihydroxybenzoateAMP ligase: demonstration of enzyme-bound (2,3-dihydroxybenzoyl)adenylate product. Biochemistry 28, 6827-6835. doi: 10.1021/bi00443a008

Rusnak, F., Liu, J., Quinn, N., Berchtold, G. A., and Walsh, C. T. (1990). Subcloning of the enterobactin biosynthetic gene entB: expression, purification, characterization and substrate specificity of isochorismatase. Biochemistry 29, 1425-1435. doi: 10.1021/bi00458a013

Simon, R., Priefer, U., and Puhler, A. (1983). A broad host range mobilization system for in vivo genetic engineering: transposon mutagenesis in gram negative bacteria. Nat. Biotech. 1, 784-791. doi: 10.1038/nbt1183-784

Simpson, L. M., and Oliver, J. D. (1983). Siderophore production by Vibrio vulnificus. Infect. Immun. 41, 644-649.

Skaar, E. P. (2010). The battle for iron between bacterial pathogens and their vertebrate hosts. PLoS Pathog. 6:e1000949. doi: 10.1371/journal.ppat.10 00949

Sousa, E. H., Garay, P. A., Tinianow, J. N., and Gerber, N. C. (2006). Development of a spectrophotometric assay for cyclase activity. Anal. Biochem. 348, 57-63. doi: 10.1016/j.ab.2005.10.008

Stelma, G. N. Jr., Reyes, A. L., Peeler, J. T., Johnson, C. H., and Spaulding, P. L. (1992). Virulence characteristics of clinical and environmental isolates of Vibrio vulnificus. Appl. Environ. Microbiol. 58, 2776-2782.
Storz, G., and Imlay, J. A. (1999). Oxidative stress. Curr. Opin. Microbiol. 2, 188-194. doi: 10.1016/S1369-5274(99)80033-2

Strom, M. S., and Paranjpye, R. N. (2000). Epidemiology and pathogenesis of Vibrio vulnificus. Microbes Infect. 2, 177-188. doi: 10.1016/S1286-4579(00)00270-7

Wang, Z., and Brecher, P. (1999). Salicylate inhibition of extracellular signalregulated kinases and inducible nitric oxide synthase. Hypertension 34, 1259-1264. doi: 10.1161/01.HYP.34.6.1259

Wendel, A. (1987). Measurement of in vivo lipid peroxidation and toxicological significance. Free Radic. Biol. Med. 3, 355-358. doi: 10.1016/S08915849(87)80047-3

Wright, A. C., Simpson, L. M., and Oliver, J. D. (1981). Role of iron in the pathogenesis of Vibrio vulnificus infections. Infect. Immun. 34, 503-507.

Conflict of Interest Statement: The authors declare that the research was conducted in the absence of any commercial or financial relationships that could be construed as a potential conflict of interest.

Received: 20 November 2013; paper pending published: 16 December 2013; accepted: 03 January 2014; published online: 24 January 2014.

Citation: Tan W, Verma V, Jeong K, Kim SY, Jung C-H, Lee SE and Rhee JH (2014) Molecular characterization of vulnibactin biosynthesis in Vibrio vulnificus indicates the existence of an alternative siderophore. Front. Microbiol. 5:1. doi: 10.3389/fmicb. 2014.00001

This article was submitted to Aquatic Microbiology, a section of the journal Frontiers in Microbiology.

Copyright (c) 2014 Tan, Verma, Jeong, Kim, Jung, Lee and Rhee. This is an openaccess article distributed under the terms of the Creative Commons Attribution License (CC BY). The use, distribution or reproduction in other forums is permitted, provided the original author(s) or licensor are credited and that the original publication in this journal is cited, in accordance with accepted academic practice. No use, distribution or reproduction is permitted which does not comply with these terms. 